\title{
Atividades em Geociências na Educação Infantil baseadas em Desenho Universal de Aprendizagem como ferramenta para o desenvolvimento da criança
}

\author{
Geoscience Activities in Child Education based on Universal Design Learning as a tool for child development \\ Lúcia Helena Martins Gonçalves ${ }^{1}$, Édino de Almeida Grama², Ana Paula Dantas Passos ${ }^{3}$ \\ 1 - Mestranda do Programa de Pós-Graduação em Ensino e História de Clências da Terra (PehCT). Universidade Estadual de Campinas (Unicamp), Campinas, SP, Brasil. \\ 2 - Mestrando do Programa de Pós-Graduação em Ensino e História de Clências da Terra (PeHCT). Universidade Estadual de Campinas (Unicamp), Campinas, SP, Brasil. \\ 3 - Ph.D, Kidlab Education \& Research, Mogi das Cruzes, SP, Brasil. \\ E-MAll: GONCALVES.LUCIAHELENAM@gmall.com, EDINOGRAMA@gmall.com, APPASSOSUSP@gmaIl.com.
}

\begin{abstract}
The approaches of Geosciences in Early Childhood Education are incipient due to the lack of knowledge of the teacher, both on the contents of Geosciences, and on the real learning needs of the child arising from his/her own development. This last aspect is particular to each child and, therefore, distinguishes children of the same age group. This article strongly encourages the development of Geosciences activities in Early Childhood Education, but there are some requirements: (i) considering the development phase to determine the learning objective; (ii) adopting the concepts in Geosciences as a background; and (iii) planning the execution in accordance with the principles of the Universal Learning Design, so that all children, regardless of the stage of development they are in, are able to carry them out with peace of mind. The article is the result of a discipline called "Special Topics in EHCT: Teaching and History of Earth Sciences in an inclusive perspective for people with disabilities", Unicamp, SP.
\end{abstract}

Resumo: As abordagens de Geociências na Educação Infantil são incipientes por falta de conhecimento do professor, tanto dos conteúdos em Geociências, quanto das necessidades reais de aprendizagem da criança advindas de seu próprio desenvolvimento. Este último aspecto é particular para cada criança e, portanto, distingue crianças de uma mesma faixa etária. Este artigo estimula fortemente que a elaboração de atividades em Geociências na Educação Infantil, mas assinala ser necessário: (i) considerar a fase de desenvolvimento para determinar o objetivo de aprendizagem; (ii) utilizar os conceitos em Geociências como pano de fundo; e (iii) planejar a execução de acordo com os princípios do Desenho Universal de Aprendizagem, para que todas as crianças, independentemente da fase do desenvolvimento em que se encontrem, consigam realizá-las com tranquilidade. 0 artigo resulta de uma disciplina denominada "Tópicos Especiais em EHCT: Ensino e História de Ciências da Terra numa perspectiva inclusiva para pessoas com deficiência", Unicamp, SP.
Citation/Citação: Gonçalves, L. H. M., Grama, É. A., \& Passos, A. P. D. (2021). Atividades em Geociências na Educação Infantil baseadas em Desenho Universal de Aprendizagem como ferramenta para 0 desenvolvimento da criança. Terræ Didatica, 17(Publ. Contínua), 1-9, e021029. doi: 10.20396/td.v17i0.8664913.

Keywords: Geoscience, Inclusive Education, Child Development, Child Education, National Common Curricular Base.

Palavras-chave: Geociências, Educação Inclusiva, Desenvolvimento Infantil, Educação Infantil, Base Nacional Comum Curricular.

\section{Manuscript/Manuscrito:}

Received/Recebido: 09/03/2021

Revised/Corrigido: 25/08/2021

Accepted/Aceito: 13/09/2021

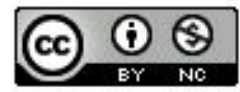

\section{Introdução e Contexto}

No Brasil, a Educação Infantil, primeira etapa da Educação Básica, atende as crianças que não completaram 6 anos de idade até o dia 31 de março e está dividida em 3 faixas etárias: 1- Bebês (zero a 1 ano e 6 meses), 2-Crianças bem pequenas (1 ano e 7 meses a 3 anos e 11 meses) e 3 -Crianças pequenas (4 anos a 5 anos e 11 meses), sendo obrigatória a todas as crianças partir dos 4 anos de idade (Brasil, 2018). O período entre zero e seis anos é denominado Primeira Infância, segundo o Marco Legal da Primeira Infância (Lei n 13.275/16) (Brasil, 2016), sendo considerado a fase mais importante do desenvolvimento humano.
Durante os seis primeiros anos de vida a criança encontra-se mais sensível aos estímulos que recebe e às experiências que vive: o que acontece nos primeiros anos de vida é de extrema importância, não somente porque promove uma marca indelével no bem estar do adulto, mas também porque determina o quão robustos ou frágeis serão os estágios subsequentes (Philips \& Shonkoff, 2000). A partir dos 4 anos de idade, quando é obrigatória a matrícula da criança em escolas de Educação Infantil, observa-se na criança o crescimento da atividade simbólica - com as brincadeiras de "faz-de-conta", do raciocínio científico, do pensamento social e do julgamento moral (Piaget, 1960); é quando a crian- 
ça deve ser "educada nos sentidos", pois é por meio deles que a criança ordena seu próprio ambiente e sua própria personalidade, ordenando o mundo interior de sua mente em um trabalho psicológico que é profundo (Montessori, 1964); quando os gestos e as representações atingem uma narrativa e um "faz-de-conta" que ilustra o desdobramento da realidade. É também o período no qual ela passa a se autoconhecer, a conhecer o próprio corpo, tendo, a motricidade, papel essencial na representação mental (Wallon, 1989). Esses são alguns dos motivos pelos quais uma criança não aprende como um adulto: durante a Primeira Infância a aprendizagem está intimamente relacionada e dependente do desenvolvimento da criança, enquanto que, no adulto, aprender depende da aquisição de conhecimento (Wallon, 1989).

No Brasil, a Base Nacional Comum Curricular (BNCC) não divide a Educação Infantil em disciplinas ou componentes curriculares. A proposta é que a aprendizagem se desenvolva em situações lúdicas, articuladas por campos de experiência, que devem ser trabalhados respeitando os direitos de aprendizagem (o direito de conviver, de brincar, de participar, de explorar, de expressar-se e de conhecer-se) (Brasil, 2018).

As Ciências da Terra ou Geociências têm como objeto de conhecimento o planeta Terra e fazem uso de diversas disciplinas para estudar a hidrosfera, litosfera, atmosfera, biosfera e suas inter-relações (Bacci, 2009). Quando trabalhadas com as crianças, dão a elas o conhecimento e a capacidade de tirar conclusões acerca de diferentes assuntos, podendo despertá-las para o que acontece à sua volta, para o seu ambiente e para os processos que nele acontecem (Orion, 2001).

As Diretrizes Curriculares Nacionais para Educação Infantil (DCNEI) (Brasil, 2009) orientam escolas a oferecer projetos interessantes e significativos que incentivem a curiosidade, a exploração, o encantamento, o questionamento, a indagação e o conhecimento das crianças em relação ao mundo físico e social, ao tempo e à natureza. Entretanto, ao elaborar as atividades, é preciso considerar que crianças de uma mesma turma podem ter diferentes habilidades por estar em diferentes fases de desenvolvimento (Bransford, 2007). Para que os projetos alcancem todas as crianças é preciso pensar currículos, espaços e tempos na perspectiva do Desenho Universal de Aprendizagem (DUA, ou Universal Design for Learning, UDL), pois este último contribui para um currículo que responde à diversidade e maximiza as oportunidades de aprendizagem e de participação dos sujeitos aprendizes (Restrepo, 2018).

O Desenho Universal de Aprendizagem foi proposto em decorrência do conceito de Design Universal apresentado por Ron Mace no campo da arquitetura, nos anos 1970 (King-Sears, 2009), sendo associado às descobertas em neurociência por David Rose, Anne Mayer e seus colegas do Center for Applied Special Technology (CAST) para ser aplicados às práticas pedagógicas (Nunes \& Madureira, 2015). Os princípios do campo da arquitetura que o norteiam são: uso equitativo, flexibilidade de uso, uso simples e intuitivo, informação perceptível, tolerância a erros, baixo esforço físico e tamanho e espaço adequados para abordagem e uso (King-Sears, 2009). No campo da neurociência, tem-se: 1. Proporcionar múltiplas formas de envolvimento; 2. Proporcionar múltiplas formas de representação; e 3. Proporcionar múltiplas formas de ação e de expressão (Nunes \& Madureira, 2015). Seguindo tais princípios, o desenvolvimento de práticas pedagógicas permite o acesso ao currículo, a participação e o progresso de todos os alunos independentemente das suas capacidades (Nunes \& Madureira, 2015). Em uma turma de Educação Infantil, em que cada criança encontra-se em uma fase diferente de seu desenvolvimento, não somente cognitivo, mas também afetivo e motor, currículos baseados nos princípios do Desenho Universal de Aprendizagem tornam-se imprescindíveis.

Apesar do potencial existente no trabalho das Ciências da Terra com crianças pequenas de se explorar os Campos de Experiências da BNCC e de se promover os estímulos necessários para o desenvolvimento dessa faixa etária, poucas publicações abordam o ensino de Geociências na Educação Básica. Silva (2018) defende que a escassez de trabalhos com Ciências da Terra para os anos iniciais pode estar relacionada à: (i) formação dos professores, (ii) materiais didáticos e (iii) à forma "incipiente" que as Geociências são abordadas nos currículos.

\section{Objetivo}

O objetivo deste trabalho é mostrar que a elaboração de práticas em Geociências na Educação Infantil depende de um conhecimento básico dos conceitos em Geociências por parte dos professores e do respeito à fase do desenvolvimento em que cada criança se encontra, sendo que, este último, pode ser garantido elaborando atividades baseadas 
nos princípios do Desenho Universal de Aprendizagem $(U D L=$ Universal Design Learning $)$.

Considerando a obrigatoriedade de toda criança a partir dos 4 anos estar matriculada em uma escola de Educação Infantil, este trabalho busca, em termos de objetivos específicos: (i) identificar as fases do desenvolvimento da criança pequena (entre $4 \mathrm{e}$ 5 anos e 11 meses de idade); (ii) apresentar alguns conceitos de Geociências necessários aos professores para ser desenvolvidos na Educação Infantil; e (iii) apresentar atividades que exemplifiquem uma elaboração abordando conceitos em Geociências a partir dos marcos de desenvolvimento infantil de crianças entre 4 e 5 anos e 11 meses e dos princípios do $U D L$.

\section{Materiais, Métodos e Técnicas}

Para a consecução do objetivo específico (i), foi realizado levantamento bibliográfico a partir de bases de pesquisa de consultas online no SciELO, Google, Google Scholar, Medline, Pubmed, banco de teses, livros e revistas especializadas em Aprendizagem, Pedagogia, Desenvolvimento Infantil e Neurociência, utilizando como descritores, de forma isolada ou conjugada, as seguintes palavras: Educação Infantil, Desenvolvimento Infantil, Child Development, Cognition, Motricity, Aprendizagem, Learning, UDL, Desenho Universal de Aprendizagem.

Para o objetivo específico (ii) foram selecionados os objetivos de aprendizagem da Base Nacional Comum Curricular (BNCC) que possibilitam o trabalho de conceitos de Geociências na Educação Infantil da criança pequena ( 4 e 5 anos e 11 meses), por nortear a formulação dos currículos nos sistemas e redes escolares de todo o Brasil.

Com relação ao objetivo específico (iii), são apresentadas atividades criadas pelos próprios autores deste trabalho que obedecem aos seguintes critérios: 1) abordam ao menos um conteúdo relacionado a Geociências; 2) trabalham ao menos um dos itens dos campos de experiências preconizados pela BNCC; 3 ) estão de acordo com os três princípios pedagógicos do UDL advindos da neurociência e com os sete advindos da arquitetura; e 4) trabalham ao menos um aspecto relacionado ao desenvolvimento infantil de crianças pequenas (4 a 5 anos e meio de idade).

Os dados encontrados sobre o desenvolvimento infantil entre 4 e 5 anos e 11 meses e os objetivos de aprendizagem selecionados da BNCC, tendo como critério os conteúdos em Geociências, são apresentados em forma de tabela para melhor visualização e consulta, por parte do educador, no planejamento e elaboração de atividades. As atividades sugeridas estão descritas em termos de: a) marcos de desenvolvimento; b) conceito de Geociências; c) campo de experiência da BNCC; d) objetivo de aprendizagem de acordo com a BNCC; e) materiais necessários; f) metodologia para a realização da atividade; e g) UDL.

\section{Resultados e Discussão}

O desenvolvimento infantil é um processo dinâmico; promover as condições para que ocorra de forma saudável depende de se conhecer como ele acontece ao longo da primeira infância. As habilidades que caracterizam cada faixa etária são chamados de marcos de desenvolvimento e são particulares para cada criança - crianças de mesma idade podem apresentar habilidades diferentes (Bransford, 2007). Entretanto, todas as crianças passam pelos mesmos marcos, isto é, uma criança só conseguirá andar após músculos, articulações e ossos apresentarem as condições favoráveis para esta habilidade; o tempo que isto levará dependerá dos estímulos oferecidos por seus cuidadores (Bruner, 2002, Wallon, 1989).

Passos (2019), estudando aspectos relacionados ao desenvolvimento durante a Primeira Infância, reuniu as pesquisas realizadas nos últimos 40 anos sobre o tema de modo que pais, educadores e cuidadores pudessem acompanhar os marcos do desenvolvimento infantil e, ao mesmo tempo, promover os estímulos mínimos necessários para a faixa etária. Na Tabela 1, são transcritos os marcos de desenvolvimento e os estímulos cognitivos e motores de crianças entre 3 e 6 anos de idade descritos pela autora. Apesar do presente trabalho considerar a faixa etária correspondente à criança pequena (de 4 a 5 anos e meio), optou-se por disponibilizar a faixa etária dos 3 aos 6 anos pelo fato de o desenvolvimento durante a infância depender diretamente dos estímulos que a criança recebe e do ambiente social e cultural no qual ela está inserida, podendo, a criança, apresentar aspectos anteriores ou posteriores àqueles esperados para sua idade como reflexo do ambiente em que vive (Passos, 2019).

O ensino de Geociências, no contexto da educação básica, encontra-se disperso nas disciplinas de Ciências e Geografia (Ernesto et al., 2018). Com raras exceções, os tópicos geocientíficos são

\begin{tabular}{c|c|c|c|c|c}
\hline (C) Terrae Didat. & Campinas, SP & v.17 & $1-9$ & e 021029 & 2021 \\
\hline
\end{tabular}


tratados de forma fragmentada, dispersa e desatualizada, não conseguindo promover a compreensão da Terra como um sistema complexo e dinâmico, além de os professores não estarem, em sua maioria, preparados para discuti-los (Oliveira et al., 2011).

A BNCC (Brasil, 2018) não divide a Educação Infantil em disciplinas ou componentes curriculares, mas sim, nos seguintes campos de experiências:

1) O eu, o outro e o nós;

2) Corpo, gestos e movimentos;

3) Traços, sons, cores e formas;

4) Escuta, fala, pensamento e imaginação;

5) Espaço, tempo, quantidades, relações e transformações.

Os "Campos de Experiências" devem estar articulados entre si e respeitar os direitos de conviver, brincar, participar, explorar, expressar-se e conhecer-se. Na Tabela Suplementar 2 (vide Suplemento do artigo), encontram-se identificados os objetivos de aprendizagem dos campos de experiências, para os quais poderão ser inseridos conceitos relacionados às Geociências, facilitando a elaboração de atividades para a Educação Infantil alinhada às propostas da BNCC.

Além de incipientes, as práticas que abordam conteúdos em Geociências na Educação Infantil, quando encontradas, não trazem informações precisas sobre quais marcos de desenvolvimento estariam sendo trabalhados, tampouco sobre o uso do UDL. Neste artigo, estes pontos são de fundamental importância para a elaboração de atividades para as crianças pequenas. Isto posto, a seguir, são descritas duas atividades em Geociências para crianças pequenas, no intuito de exemplificar o uso das das Tabelas Suplementares 1 e 2 dos princípios do $U D L$ para a elaboração das atividades. A descrição apresenta: a) os marcos de desenvolvimento; b) uma breve descrição do conceito de Geociência a ser conhecido pelo professor; c) o campo de experiência da BNCC correspondente; d) o objetivo de aprendizagem de acordo com a BNCC em seus códigos como apresentados na tabela 02; e) materiais necessários; f) a metodologia para a realização da atividade; e g) as ações que justificam cada um dos princípios do $U D L$.

\section{Atividade 1. Montando as Placas Tectônicas}

a) Marcos de Desenvolvimento: Começa a corrigir a orientação das formas; faz sinal com o polegar para cima (movimentos com o polegar opositor); habilidade para cortar, misturar e amassar a própria comida e item de mesma textura; monta um colar de contas; brinca com jogo de tabuleiro; constrói torres com mais de 10 cubos; pinta desenhos desajeitadamente; segura e usa o lápis usando 3 dedos com bom controle; atento para tarefas simples; pensa de mais de uma maneira; gosta de jogar jogos; pode construir uma torre vertical com cubos; aperta fortemente com cada mão; pode desenhar com certo nível de detalhe.

b) Conceito em Geociências: Placas Tectônicas são fragmentos rochosos da litosfera (camada da crosta e parte do manto superior) divididas em treze placas principais (Africana, Antártida, Arábica, Australiana, Caribenha, de Cocos, Euroasiática, das Filipinas, Indiana, de Nazca, Norte-americana, Pacífica e Sul-americana) que apresentam movimentos convergentes (encontro entre placas), que formam as cordilheiras; divergentes (afastamento das placas), que formam as depressões; e transformante (deslizamento horizontal entre as placas), que formam as falhas geológicas. Cordilheiras, depressões e falhas geológicas formam o relevo (Press, et al., 2006).

c) Campos de Experiências (BNCC): "Espaços, Tempos, Quantidades, Relações e Transformações”; "Corpos, Gestos e Movimentos"; "O Eu, O Outro e O Nós".

d) Objetivo de Aprendizagem (BNCC): EI03CG05; EI03EO02; EI03CG02; EI03ET01; EI03ET03.

e) Materiais necessários: 1) Quebra-cabeça de madeira ou papelão nas dimensões $400 \mathrm{~mm}$ altura $\mathrm{x}$ $600 \mathrm{~mm}$ comprimento $\times 3 \mathrm{~mm}$ de espessura, com 13 peças grandes, cada uma representando uma placa tectônica. O formato das bordas do quebra-cabeças respeitará o formato das bordas das placas tectônicas, representando: os movimentos convergentes, com bordas mais elevadas (simulando as cordilheiras); os dos divergentes, com as bordas mais baixas (as depressões); e o transformante, com sulcos (as falhas geológicas). 2) Ilustração no tamanho A3 com a representação das placas tectônicas delimitadas, com destaque para as formas do relevo que foram representadas pelas diferentes texturas que estão nas peças do quebra-cabeça. 3) tecido para a criança vendar os próprios olhos. 
f) Metodologia: O educador demonstra como a criança usa a venda em si mesmo e pede para a criança repetir em si mesma até que ela o consiga fazer sozinha sem grandes esforços. Em seguida, dispõe as peças do quebra-cabeça, a ilustração das placas tectônicas e a venda sobre a mesa ou chão e deixa a criança manusear as peças livremente. É importante que o educador não corrija a criança na montagem do quebra-cabeça, permitindo a exploração das peças de diferentes maneiras. Toda forma possível de exploração é importante para que a criança resolva, dentro de si, intuitivamente, o princípio das placas tectônicas, sua forma e tamanho e como elas se organizam numa representação plana da Terra. A criança poderá montar o quebra-cabeça sozinha ou com colegas, com os olhos vendados ou não, se assim preferir.

g) Princípios do UDL: 1) uso simples e intuitivo: processo de encaixe simples e de montagem intuitiva das peças; 2) uso equitativo: favorece o manuseio e preserva a integridade da criança e do material e pensado para ser utilizado utilizando o sentido da visão e/ou do tato; 3 ) tolerância a erros: o professor não corrige a criança no manuseio das peças em respeito ao brincar livre da criança; 4) flexibilidade de uso: manuseio das peças pela criança é livre (ela pode, por exemplo, ordenar e categorizar as peças antes de decidir montá-lo) e as diferentes texturas que se complementam entre as peças possibilitam o uso somente do tato; 5) tamanho e espaço adequado para a abordagem e uso: as crianças poderão montar em uma mesa na altura delas ou no chão; 6) informação perceptível: as peças do quebra-cabeça terão texturas e formas como apresentadas na imagem de referência, levando a criança a tentar encaixá-las e ordená-las naturalmente; 7) baixo esforço físico: o quebra cabeças respeita o tamanho, peso e a habilidade de encaixe correspondente de à faixa etária (peças com tamanho mínimo equivalente ao tamanho da mão da criança). No campo da neurociência, atende as múltiplas formas de representação (placas tectônicas do formato de peças de quebra-cabeça com texturas e imagem impressa), de envolvimento (brincar livre sozinha, envolvida com a atividade, ou com os colegas) e de ação e expressão (ao experimentar diferentes maneiras de manipular e organizar as peças).

\section{Atividade 2. Quanto Tempo o Tempo Geológico Tem?}

a) Marcos de Desenvolvimento: Faz-de-conta mais elaborado; gosta de histórias mais complexas e gosta de ouvi-las várias vezes; desenvolve o comportamento simbólico; tenta explicar o que acontece no mundo que a rodeia; conta histórias; entende a ideia de contar; entende a ideia de "igual e "diferente"; conta o que acha que vai acontecer depois de uma história; cria hipóteses; pergunta o significado das palavras; conta uma história simples; entende conceitos de tempo e sequência e usa termos como primeiro e último; conta até 10; desenvolvimento de leitura e escrita por conta própria; pensa de mais de uma maneira e guarda várias ideias de uma vez; gosta de aprender sobre natureza e ciência.

b) Conceito em Geociências: Tempo Geológico: referencial temporal passivo onde ocorrem eventos geológicos e bióticos de larga escala (Dodick \& Orion 2003). Para esta atividade, são trabalhadas as Eras Geológicas definida por Branco (2016): cada era geológica corresponde ao estado em que os continentes, oceanos e seres vivos estavam distribuídos pela Terra em diferentes momentos do Tempo geológico, tendo assim, um conjunto de características que são mais marcantes em cada uma delas. Esse recorte dentro do tempo geológico foi pensado como alternativa para introduzir e trabalhar a noção de tempo juntamente com o surgimento dos seres vivos. Assim sendo, para essa atividade serão consideradas as eras: Paleoarqueano (3,6 a 3,2 bilhões de anos), marcado pelo surgimento das primeiras bactérias; Paleoproterozoico (de 2,5 a 1,6 bilhões de anos), caracterizado pelo surgimento dos primeiros seres eucariontes, como a ameba; Paleozóico (542 a 251 milhões de anos), com o desenvolvimento de um grande número de invertebrados, principalmente marinhos, como os trilobitas; Mesozoico (entre 251 milhões e 65,5 milhões de anos), conhecido pelo surgimento, domínio e extinção dos dinossauros; e Cenozoico (de 65,5 milhões de anos até os dias atuais), marcado pelo surgimento dos mamíferos, incluindo o ser humano (Branco, 2016).

c) Campos de Experiências (BNCC): "Espaços, Tempos, Quantidades, Relações e Transformações"; "Corpos, Gestos e Movimentos"; "Escuta, Fala, 
Pensamento e Imaginação"; "O Eu, O Outro e O Nós”.

d) Objetivos de Aprendizagem (BNCC): EI03ET04: EI03ET03; EI03ET06; EI03EO04; EI03CG02; EI03EF09; EI03ET06; EI03ET07.

e) Materiais: 1) Tabelas táteis que irão representar a "linha do Tempo Geológico", com imagens que caracterizam cada Era Geológica e, em relevo (papelão com $3 \mathrm{~mm}$ de espessura) os seres vivos que caracterizam cada Era. 2) Tabela da representação da rotina da criança. Para a construção das duas tabelas, são necessários os seguintes materiais: barbante $\mathrm{n}^{\circ} 12$, papelão, folha sulfite A3 ou cartolina A3, lápis de escrever, lápis de cor, borracha, objetos da rotina das crianças, "geleca", comprimido de cápsula, linha de costura.

f) Metodologia: Previamente, o educador elaborará a tabela tátil da linha do Tempo Geológico e a tabela da rotina da criança. Na linha do Tempo Geológico, as colunas devem respeitar a duração de cada Era quando comparadas entre si (Eras que duraram menos tempo terão colunas de largura menor comparativamente àquelas que duraram mais). As linhas das colunas serão delimitadas com barbante $n^{\circ} 12$. Cada era será representada com imagens e com um ser vivo em relevo que a caracteriza. A bactéria será representada por um comprimido em cápsula com um pedaço de $1 \mathrm{~cm}$ de linha de costura colado em uma das extremidades. A ameba será representada por um pote de "geleca". Os animais serão representados em papelão com $3 \mathrm{~mm}$ de espessura com seu contorno e as texturas, por ranhuras no papelão, quando pertinente. Para a tabela da rotina da criança, o educador dividirá a folha de $\mathrm{A} 3$ nas colunas que representarão a rotina das crianças, sendo que o tamanho de cada coluna respeitará a duração do tempo de cada atividade (atividades de curta duração terão a coluna mais estreita que as de longa duração). A folha de A3 deverá ser colocada dobrada ao meio de modo que metade seja colocada na parede e a outra metade, em uma mesinha que deverá ser encostada num ângulo de $90^{\circ}$ com a folha para a colocação dos objetos que representarão cada rotina das crianças (ex.: uma caneca para o horário da merenda, pote transparente com a areia do parquinho para representar o recreio etc.). A tabela com a linha do Tempo Geológico deverá ser colocada ao lado direito da tabela de rotina por conta do sentido de leitura ocidental (da esquerda para a direita).

No primeiro dia da atividade, o educador leva à sala de aula diversos objetos que podem caracterizar as rotinas das crianças; pergunta a elas quais objetos representam melhor cada período do dia; e o coloca na coluna específica da tabela de rotina, exemplificando o procedimento. Nos dias subsequentes, a criança estará responsável por colocar todos os objetos, montando a rotina do dia, retirando-os após ter vivenciado determinado período. Todas as crianças devem realizar esta atividade, independentemente de quaisquer limitações. Quanto à tabela do Tempo Geológico, a criança estará livre para explorar usando o tato e/ou a visão.

\section{Discussão e interpretação de resultados}

Para desenvolver ferramentas pedagógicas eficientes, o professor precisa estar familiarizado com as disciplinas que leciona e entender a relação entre as informações e os conceitos que ajudam a organizá-las em um determinado campo do conhecimento. Além disso, é igualmente importante que o professor compreenda como evolui o raciocínio dos aprendizes e como ele se desenvolve dentro dos conceitos (Bransford, 2007). Na Educação Infantil, a evolução do raciocínio da criança está diretamente relacionada ao seu desenvolvimento, pois é no período entre zero e seis anos de idade que se estabelecem as bases cognitivas, motoras e afetivas que valerão para os anos subsequentes (Piaget, 1960, Montessori, 1964, Wallon, 1989, Bruner, 2002, Passos, 2019). Nesse contexto, a Tabela Suplementar 1 constitui uma ferramenta importante para o professor de Educação Infantil, que pode consultá-la para, a partir das habilidades das crianças por ele observadas, localizar-se no marco de desenvolvimento em que a criança se encontra e saber os estímulos mínimos necessários para cada marco, para então, elaborar atividades que correspondam às necessidades reais de aprendizagem da criança.

O manual de orientações pedagógicas - Brincadeiras e Interações nas Diretrizes Curriculares para a Educação Infantil (Brasil, 2012) coloca que a criança experimenta as situações do mundo físico por meio dos sentidos e destaca a importância do papel do adulto como aquele responsável por proporcionar materiais e tempo para brincar, obser- 
vando e desenhando situações que transformam o mundo físico, utilizando água, areia e terra, e que, ao brincar, a criança vai compreendendo o mundo ao seu redor. Entretanto, o que será trabalhado em torno das práticas, a seleção e acomodação dos materiais da dinâmica da experiência em si, pensando na prática do $U D L$, deve ser visto com cuidado pelo educador, bem como as orientações e comentários que serão feitos durante a atividade para que a aprendizagem se torne significativa. Trabalhar com diferentes materiais permite que eles sejam entendidos e classificados dentro do "mundo" da criança, colaborando para a criação de hipóteses e definições sobre o mundo físico em uma linguagem que é própria dessa faixa etária. Quando o educador permite que as crianças testem, criem, descubram formas e como fazer, o sentido dado à experiência faz com que o conhecimento passe a se tornar mais organizado e estruturado (Santos et al., 2019). Dessa forma, o conteúdo não é colocado como o principal ponto do trabalho, mas sim, o modo que o aprender, a descoberta e o brincar se dão em torno dessa experiência.

$\mathrm{Na}$ Tabela Suplementar 2, foram colocados os objetivos de aprendizagem da BNCC que se relacionam com diferentes conceitos em Geociências. Aliada à Tabela Suplementar 1, o educador encontra os conhecimentos necessários para a elaboração de atividades que utilizem os conceitos em Geociências para a promoção do desenvolvimento da criança, auxiliando-o no discernimento de quais conceitos são mais relevantes para seu conhecimento.

Para Restrepo (2018), a primeira infância é o período da vida mais importante por assentar as bases para o desenvolvimento da inteligência e da personalidade. É quando se obtém o máximo desenvolvimento do cérebro, da linguagem e do pensamento. A atenção à diversidade, a partir de uma perspectiva de direitos, reconhece as crianças como sujeitos com uma identidade específica que deve ser respeitada e valorizada como parte essencial de seu desenvolvimento, seres únicos com formas próprias de aprender e de se expressar. $\mathrm{O}$ Desenho Universal de Aprendizagem é um modelo concebido no intuito de apresentar a informação de acordo com os estilos e estratégias das crianças, favorecendo as possibilidades de aprendizagem e a participação efetiva de todos os aprendizes e, ao educador, orientar seus espaços pedagógicos com metodologias flexíveis e alternativas que abarcam as singularidades e as identidades de cada sujeito
(Restrepo, 2018). Sob este aspecto, o brincar livre se torna fundamental na Educação Infantil, pois permite que a criança use sua criatividade enquanto desenvolve a imaginação, a destreza e a força física, emocional e cognitiva, explorando o mundo ao redor (Ginsburg, 2007). Neste contexto, as atividades 1 e 2 aqui propostas são um exemplo do respeito aos estilos e estratégias de aprendizagem resultantes do desenvolvimento da criança pelo fato de sua execução estar baseada nos princípios do UDL.

Ao analisar a Atividade 1, "Montando as Placas Tectônicas", percebe-se que ela tem caráter inclusivo, uma vez que o tamanho e peso das peças auxiliam na manipulação, ao mesmo tempo em que as diferentes texturas influenciam (e facilitam) o uso do tato no cumprimento desse desafio. Também promove o brincar livre, ao permitir a criança explorar as peças de todas as maneiras que desejar (ordenando e categorizando por cor, forma, textura, tamanho; empilhando; testando os diferentes encaixes; montando outras formas), até que se esgotem todas as possibilidades de compreensão e aprendizagem. Nesse momento, o interesse da criança pela atividade diminui, indicando que ela está pronta para uma atividade mais complexa (Montessori, 1964). É importante que o professor respeite o brincar livre não corrigindo a criança pelo manuseio das peças pois, o que pode ser considerado "erro", é, na verdade, as diferentes formas de aprendizagem (Piaget, 1960, Montessori, 1964, Bruner, 2002). Corrigir a criança neste momento de exploração pode provocar tensão suficiente para impedir o processo de aprendizagem pelo cérebro (Willis, 2010).

Na Atividade 2, "Quanto Tempo o Tempo Geológico Tem?”, a criança é estimulada, primeiramente, a pensar em uma pequena história sobre si mesma ao montar sua rotina todos os dias, entendendo conceitos como "começo" e "fim", "primeiro" e "último". A atividade é aplicável a uma faixa etária em que a criança é imaginativa, conta histórias, está envolvida no "faz-de-conta" e inicia a compreensão de tempo como sequência. Ao colocar uma tabela ao lado da outra, a criança naturalmente fará comparações entre elas: entendendo a noção do próprio tempo, ela poderá expandir para a noção do tempo do outro, no caso, do planeta. A atividade é importante para a criança estabelecer as bases necessárias para relacionar os conceitos desenvolvidos em placas tectônicas (Atividade 1) com a formação dos continentes a partir de Pangea e, posteriormente, a formação das rochas. A diferença das larguras das colunas nas tabelas é importante para, mais adiante,

\begin{tabular}{c|c|c|c|c|c}
\hline (C) Terrae Didat. & Campinas, SP & v.17 & $1-9$ & e 021029 & 2021 \\
\hline
\end{tabular}


quando a criança passar a compreender os números como entidades individuais e não necessariamente sequenciais (isto é, quando, a existência do número 3 não depender do que vem antes, o 2, e do que vem depois, o 4, para existir, por exemplo) (Devlin, 2010), ela tenha as bases para a compreensão de duração do tempo, da divisão do tempo em períodos e de independência entre os períodos, apesar de serem sequenciais (essenciais para a leitura de relógio analógico) (Piaget, 1960, Bruner, 2002).

Como se pode perceber, proporcionar atividades que trabalhem os sentidos das crianças, tendo em vista o estímulo ao seu processo de desenvolvimento e descoberta, poderá auxiliar na construção de importantes relações pelo próprio educando. Sob esta ótica, a abrangência de assuntos geocientíficos pode proporcionar as variadas possibilidades didático-pedagógicas necessárias ao ensino na Educação Infantil. Ao mesmo tempo, considerando que cada criança em uma mesma turma encontra-se em uma determinada fase de seu desenvolvimento, a elaboração das atividades em Geociências precisa considerar (i) a fase de desenvolvimento para determinar o objetivo de aprendizagem (Tab. 1); (ii) utilizar os conceitos em Geociências como pano de fundo (Tab. 2); e (iii) os princípios da $U D L$ para desenhar sua execução (Atividades 1 e 2) a fim de que todas as crianças, independentemente da fase do desenvolvimento em que se encontram, consigam realizar a atividade com tranquilidade. Isto posto, fica claro que as Atividades 1 e 2 são uma ferramenta valiosa para o professor de Educação Infantil pelas informações que reúnem, pois exemplificam a aplicação dos conteúdos necessários ao saber do educador contidos nas Tabelas Suplementares 01 e 02 em práticas com foco no indivíduo, no caso, a criança pequena, sob a perspectiva da $U D L$.

\section{Considerações Finais}

$\mathrm{Na}$ Educação Infantil, o educador, para elaborar as atividades, precisa conhecer a criança, como ela elabora o pensamento, como interage com o ambiente e com os outros. Para isso, ele precisa conhecer como ocorre o desenvolvimento infantil para olhar o mundo a partir da perspectiva da criança, de maneira que as atividades tenham como foco a criança e seu desenvolvimento. A aquisição de conhecimento de conceitos e conteúdos deve ser o foco para o aprimoramento das práticas do educador. Ao longo da Educação Infantil é importante trabalhar os sentidos e o afeto, para que, quando o conhecimento vivido em forma de experiências nos primeiros anos for apresentado nas etapas subsequentes de maneira formal, acadêmica, seja algo agradável e interessante de ser relembrado. Isso faz com que, em fase posterior, o estudante deseje conhecer mais e sinta prazer em aprender.

As Geociências, ao abordar os fenômenos naturais, proporcionam temas importantes que chamam a atenção e provocam a curiosidade: tudo o que constitui o planeta Terra e o Sistema Solar podem fazer parte das sequências didáticas e promover a aprendizagem por meio do desenvolvimento. Assim sendo, percebe-se que os conteúdos de Geociências, independentemente de sua complexidade, podem ser incluídos nos currículos, desde a Educação Infantil, contribuindo não só para a construção da literacia científica, mas também, e principalmente, para favorecer o desenvolvimento dos pequenos, desde que sejam apresentados respeitando os métodos de investigação e descoberta inerentes à idade da criança.

Considerando que, em uma mesma turma, diferentes crianças estão em diferentes fases de desenvolvimento, a elaboração de práticas que tenham por base os princípios do UDL auxiliaria o professor de Educação Infantil no desenvolvimento de atividades para todas as crianças, mesmo em uma turma diversa, independentemente do tipo de limitação que uma criança possa ter - seja ela decorrente da fase do desenvolvimento em que se encontra, ou por alguma deficiência física/ fisiológica que ela apresente. Ao utilizar o UDL na Educação Infantil, os direitos das crianças propostos na BNCC são respeitados, principalmente os direitos de brincar e explorar, permitindo que as crianças explorem sozinhas diferentes materiais fornecidos pelo professor. Ao criar momentos de reflexão e a partir da observação e escuta da criança, o professor poderá perceber o que é pertinente e necessário para os pequenos. Como consequência, têm-se o reconhecimento da criança como sujeito de direitos, tendo o direito de aprender e brincar em locais planejados e construídos para e com elas.

\section{Agradecimentos}

Agradecemos às professoras Fabiana Curtopassi Pioker-Hara e Rosely Aparecida Liguori Imbernon pela oportunidade de concluirmos a disciplina EH 012 "Tópicos Especiais em EHCT: Ensino de Ciências da Terra numa perspectiva inclusiva à pessoa com deficiência" com a produção deste artigo. 


\section{Referências}

Bransford, J. D. (2007). Como as pessoas aprendem: cérebro, mente, experiência e escola. Editora Senac São Paulo. 381p.

Brasil. Ministério da Educação. (1999). Diretrizes Curriculares Nacionais para a Educação Infantil (DCNEI). Resolução CNE/CEB 5/2009. Brasília: DOU 18.12.2009.

Brasil. Ministério da Educação. Secretaria de Educação Básica. (2012). Brinquedos e brincadeiras de creches: manual de orientação pedagógica. Brasília: MEC/SEB. $158 \mathrm{p}$.

Brasil. (2016). Lei 12.796/16. Marco Legal da Primeira Infância. Brasil: DOU 09.03.2016. URL: http://www. planalto.gov.br/ccivil_03/ato2015-2018/2016/lei/ 113257.htm. Acesso 06.02.2020.

Brasil. Ministério da Educação. Secretaria de Educação Fundamental. (2018). Base Nacional Comum Curricular. Brasília: MEC/SEF. URL: http://basenacionalcomum.mec.gov.br/. Acesso 31.12.2020.

Bacci, D. L. C. (2009). A contribuição do conhecimento geológico para a Educação Ambiental. Pesquisa em Debate, Edição 11, 6(2), 1-24

Bruner, J. (2002). Acción, Pensamiento y Lenguaje. 6 ed. Madrid: Alianza Editorial. 232p.

Devlin, K. (2010). The mathematical brain. In: Souza, D. A. (org.). (2010). Mind, brain, and education: neuroscience implications for the classroom. Bloomington: Solution Tree Press. p. 163-178.

Dodick, J., Orion, N. (2003). Cognitive factors affecting student understanding of geologic time. Journal of Research in Science Teaching: The Official Journal of the National Association for Research in Science Teaching, 40(4), 415-442. doi: 10.1002/tea.10083.

Ernesto, M., Cordani, U. G., Carneiro, C. D. R., Dias, M. A. F., Mendonça, C. A., \& Braga, E. D. S. (2018). Perspectivas do ensino de Geociências. Estudos Avançados, 32(94), 331-343. doi: 10.1590/ s0103-40142018.3294.0021.

King-Sears, M. (2009). Universal design for learning: Technology and pedagogy. Learning Disability Quarterly, 32(4), 199-201. doi: 10.2307/27740372.

Montessori, M. (1964). Dr. Montessori's Own Handbook. Massachusetts: Robert Bentley, Inc. 121p.

Nunes, C., \& Madureira, I. (2015). Desenho Universal para a Aprendizagem: Construindo práticas pedagógicas inclusivas. Da investigação às práticas, 5(2), 126-143. URI: http://hdl.handle. net/10400.21/5211. Acesso 31.12.2020.

Oliveira, L. A. S., Bacci, D. D. L. C., Soares, D. B., \& Silva, D. F. da (2011). O ensino de Geociências e a formação de professores: experiências de um processo de aprendizagem. Anais VIII Encontro Nacional de Pesquisa em Educação em Ciências, 1-14, URL: http://repositorio.usp.br/directbitstream/0ab45483-7230-45a6-bdfe-4005ff45c634/2928958. pdf. Acesso 03.12.2020.

Orion, N. (2001). A educação em Ciências da Terra: da teoria à prática-implementação de novas estratégias de ensino em diferentes ambientes de aprendizagem. In: Marques, L, Praia, J. (Coords.). (2001). Geociências nos currículos básico e secundário. Aveiro: Universidade. p. 93-114.

Passos, A. P. D. (2019). Integração de variáveis motoras, cognitivas, nutricionais, metabólicas e de influência epigenética relativas à Primeira Infância como uma ferramenta para investigação do Desenvolvimento Infantil. São Paulo: Inst. Biociências. USP. 450p. (Tese Doutorado). doi: 10.11606/T.41.2019.tde-27082019-092331.

Phillips, D. A., \& Shonkoff, J. P. (2000). From neurons to neighborhoods: The science of early childhood development. Washington, D.C.: The National Academies Press. 612p. doi: 10.17226/9824.

Piaget, J. (1960). Psychology of intelligence. New Jersey: Littlefield, Adams \& Co. 182p.

Press, F., Siever, R., Grotzinger, J., \& Jordam, T.H. (2006). Para entender a Terra. Porto Alegre: Bookman. 652p.

Restrepo, N. R. (2018). Diseño universal en la educación infantil. Reflexiones frente a su implementación e implicación para el proceso de enseñanza-aprendizaje. Revista Senderos Pedagógicos, 9(9), 39-56.

Santos, V. S., Machado, A. C. F., \& Rizzatti, I. M. (2019). A importância da experimentação no ensino de ciências para o entendimento do ciclo da água: uma proposta para a educação infantil. ACTIO: Docência em Ciências, 4(3), 131-145. doi: 10.3895/actio.v4n3.10416.

Silva, D. G. (2018). O ensino de Geociências no contraturno escolar decifrando a terra: possibilidades e desafios para inserção das Geociências na escola. Campinas: Inst. Geoc. Unicamp. (Dissertação de Mestrado). URL: http://repositorio.unicamp.br/jspui/handle/ REPOSIP/333213.

Wallon, H. (1989). As Origens do Pensamento na Criança. São Paulo: Ed. Manole. 527p.

Willis, J. (2010). The current impact of neuroscience on teaching and learning. In: Souza, D. A. (org.). (2010). Mind, brain and education: Neuroscience implications for the classroom. Bloomington: Solution Tree Press. 45-68p.

\section{Material Suplementar:}

Tabela Suplementar 1. Marcos do desenvolvimento de 3 a 6 anos de idade e estímulos cognitivos e motores sugeridos para a faixa etária (vide Material Suplementar)

Tabela Suplementar 2. Objetivos de aprendizagem dos "campos de experiências" da BNCC (Brasil, 2018) e os conceitos em Geociências aos quais foram identificados. Os códigos alfanuméricos identificam os objetivos de aprendizagem, sendo o primeiro par de letras referente às iniciais de Educação Infantil; o primeiro par de números ao grupo etário; e o segundo par de letras, uma referência ao campo de experiência. 0 termo ciclos naturais refere-se, por exemplo, ao ciclo da água, ao ciclo do carbono, ao ciclo das rochas (vide Material Suplementar) 